\title{
Influência da Temperatura de Sinterização nas Propriedades Físicas, Mecânicas e Microestruturais de Cerâmica Vermelha Incorporada com Cinza de Bagaço de Cana de Açúcar
}

\author{
Mônica Castoldi Borlini, João Luiz Cortat da Costa Mendonça, Carlos Maurício Fontes Vieira, \\ Sergio Neves Monteiro \\ Laboratório de Materiais Avançados - LAMAV, Centro de Ciência e Tecnologia, \\ Universidade Estadual do Norte Fluminense, LAMAV/CCT/UENF \\ Av. Alberto Lamego 2000, Parque Califórnia, Campos dos Goytacazes, Rio de Janeiro, RJ. CEP: 28013-602 \\ e-mail: monicaborlini@yahoo.com.br, joao_vasp171@yahoo.com, vieira@uenf.br, sergio.neves@ig.com.br
}

\section{RESUMO}

Esse trabalho teve por objetivo estudar a influência da temperatura de sinterização nas propriedades físicas, mecânicas e microestruturais de cerâmica vermelha incorporada com cinza de bagaço de cana de açúcar. Foram utilizadas como matérias-primas uma massa cerâmica industrial para fabricação de telhas e uma cinza de bagaço de cana de açúcar, gerada na calcinação do bagaço em caldeiras de uma indústria sucroalcooleira. Ambas as matérias-primas são provenientes da região de Campos dos Goytacazes, norte do Estado do Rio de Janeiro. Foram feitas incorporações de 0,10 e $20 \%$ de cinza com granulometria inferior a $44 \mu \mathrm{m}$ (325 mesh) na massa industrial. Os corpos de prova foram preparados por prensagem uniaxial e sinterizados a temperaturas de 900,1050 e $1200^{\circ} \mathrm{C}$. As seguintes propriedades foram determinadas: retração diametral, absorção de água e resistência mecânica por compressão diametral. Para análise microestrutural da cerâmica com incorporação de cinza foram realizados, após a sinterização a 1050 e a $1200^{\circ} \mathrm{C}$, ensaios de difração de raios-X e de microscopia eletrônica de varredura. Os resultados indicam que não houve uma mudança significativa nas propriedades físicas e mecânicas da cerâmica vermelha com incorporação de cinza. A cerâmica com incorporação de $20 \%$ de cinza, sinterizada a $1200^{\circ} \mathrm{C}$, apresentou grande diferença na microestrutura em relação às outras composições estudadas, apresentando grande formação de fase líquida.

Palavras chaves: cinza de bagaço de cana, incorporação, cerâmica vermelha, temperatura de sinterização, propriedades.

\section{Influence of the Sintering Temperature in the Physical, Mechanical and Microstructural Properties of Red Ceramic Incorporated with Sugar Cane Bagasse Ash}

\section{ABSTRACT}

This work has for objective to evaluate the influence of the sintering temperature in the physical, mechanical and microstructural properties of incorporate red ceramic with sugar cane bagasse ash. As raw materials an industrial ceramic body for production of tiles and a sugar cane bagasse ash, generated during the burning of the bagasse in boilers of an alcohol industry were used. Both raw materials were obtained from the area of Campos dos Goytacazes, north of the State of Rio de Janeiro. Incorporations of 0, 10 and $20 \%$ of ash with inferior granulometry to $44 \mu \mathrm{m}$ (325 mesh) were made in the industrial ceramic body. Specimens were prepared by uniaxial press-molding and sintered at 900,1050 and $1200^{\circ} \mathrm{C}$. The following properties were determined: diametrical shrinkage, water absorption and mechanical resistance for diametrical compression. Microstructural analysis of the ceramic incorporated with ash was accomplished, after sintering at 1050 e $1200^{\circ} \mathrm{C}$, by X-ray diffraction and scanning electron microscopy. The results indicated that there was no significant change in the physical and mechanical properties of the red ceramic incorporated with ash. The ceramic with incorporation of $20 \%$ of ash, sintered at $1200^{\circ} \mathrm{C}$, presented great difference in the microstructure in relation to the other studied compositions, due to a significant formation of liquid phase.

Keywords: cane bagasse ash, incorporation, red ceramic, sintering temperature, properties. 


\section{INTRODUÇÃO}

A produção de açúcar e álcool causa poluição do ar, que é agravada pela queima dos canaviais na época da colheita da cana, prática que gera altas emissões de partículas e gases, elevando consideravelmente os níveis de poluentes no ar da região [1].

Em Campos dos Goytacazes, município situado ao norte do estado do Rio de Janeiro, a produção de açúcar e álcool tem sido, há mais de um século, o principal item da sua economia. Apesar do declínio da indústria açucareira na metade do século passado, esta continua representando um dos maiores potenciais econômicos regionais. Há atualmente seis indústrias açucareiras na região, produzindo em torno de 300.000 toneladas de açúcar por ano.

O bagaço é o principal combustível usado nas caldeiras para a geração de energia no processamento do açúcar. O bagaço é calcinado em temperaturas por volta de $1000^{\circ} \mathrm{C}$. O resultado da calcinação do bagaço nas caldeiras é uma cinza pesada e uma cinza volante, que embora não sejam diretamente liberadas no ar como as da colheita, podem poluir o ambiente quando descartadas de forma imprópria após a limpeza das caldeiras da usina. Uma solução para esta questão é a incorporação da cinza do bagaço da cana na cerâmica. A incorporação, além de solucionar o problema da cinza do bagaço da cana, pode trazer benefícios ao produto final. Vários trabalhos têm sido realizados utilizando cinzas, em geral, em incorporação à cerâmica [2- $\underline{-}]$.

O objetivo do presente trabalho foi avaliar a influência da temperatura de sinterização nas propriedades físicas, mecânicas e microestruturais de cerâmica vermelha incorporada com cinza de bagaço de cana de açúcar.

\section{PROCEDIMENTO EXPERIMENTAL}

As matérias-primas usadas nesse trabalho foram uma cinza obtida do processo de calcinação do bagaço de cana de açúcar em caldeiras e uma massa cerâmica industrial usada na fabricação de telhas. Ambas as matérias-primas são provenientes da região de Campos dos Goytacazes, norte do Estado do Rio de Janeiro.

A composição química da cinza, determinada por espectrometria de fluorescência de raios-X [7] e da massa cerâmica pode ser visto na Tabela 1. A difração de raios-X (DRX) [7] foi usada para identificar as seguintes fases na cinza: quartzo, feldspato potássico, mulita e hematita. Na massa cerâmica foram identificadas as fases: caulinita, gibsita, mica muscovita e quartzo.

Tabela 1: Composição química da cinza e massa cerâmica (\% peso) [7]].

\begin{tabular}{|c|c|c|c|c|c|c|c|c|c|c|c|}
\hline & $\mathbf{S i O}_{2}$ & $\mathbf{A l}_{2} \mathbf{O}_{3}$ & $\mathbf{F e}_{2} \mathbf{O}_{3}$ & $\mathbf{T i O}_{2}$ & $\mathbf{K}_{\mathbf{2}} \mathbf{O}$ & $\mathbf{M g O}$ & $\mathbf{C a O}$ & $\mathbf{M n O}$ & $\mathbf{P}_{2} \mathbf{O}_{\mathbf{5}}$ & $\mathbf{Z r O}_{2}$ & $\mathbf{P F}$ \\
Cinza & 77,5 & 4,7 & 3,8 & 0,3 & 5,4 & 3,0 & 2,3 & 0,3 & 2,3 & 0,06 & 0,31 \\
Massa cerâmica & 50,2 & 27,9 & 6,0 & 1,1 & 1,2 & 0,7 & 0,2 & - & 0,2 & 0,03 & 12,4 \\
\hline
\end{tabular}

A massa cerâmica foi desintegrada e peneirada a $840 \mu \mathrm{m}$ (20 mesh). A cinza foi manualmente desaglomerada e peneirada a úmido usando peneira com abertura de $44 \mu \mathrm{m}$ (325 mesh). Foi utilizada a fração de cinza que passou pela peneira. Foram feitas incorporações de 0, 10 e $20 \%$ de cinza na massa cerâmica, como mostra a Tabela 2. As composições estudadas de massa cerâmica com a cinza foram misturadas em um moinho de bolas por 30 minutos. As misturas foram umedecidas ao nível de $8 \%$, sendo finalmente, peneiradas a $840 \mu \mathrm{m}$ (20 mesh) e guardada em sacos plásticos por 24 horas. Corpos de prova cilíndricos $\left(20,2 \times 9 \mathrm{~mm}^{2}\right)$ foram preparados por prensagem uniaxial a $20 \mathrm{MPa}$, seguido por secagem ao ar livre por 24 horas e então secagem em estufa a $110^{\circ} \mathrm{C}$ por mais 24 horas. A sinterização foi realizada em um forno elétrico a 900,1050 e $1200^{\circ} \mathrm{C}$. A taxa de aquecimento foi de $3^{\circ} \mathrm{C} / \mathrm{min}$ até que a temperatura desejada fosse alcançada, ficando nessa temperatura por 30 minutos. O resfriamento ocorreu por convecção natural, após o desligamento do forno. As seguintes propriedades foram determinadas: densidade do corpo, retração diametral, resistência mecânica por compressão diametral, o chamado Brazilian Disc Test [8] e absorção de água.

Tabela 2: Composições estudadas (\% em peso).

\begin{tabular}{|c|c|c|}
\hline Composição & Cinza & Argila \\
A0C & 0 & 100 \\
A10C325 & 10 & 90 \\
A20C325 & 20 & 80 \\
\hline
\end{tabular}


A densidade do corpo e a absorção de água foram determinadas de acordo com o procedimento padrão [9]. A retração diametral foi obtida por medidas do diâmetro das amostras antes e depois da sinterização, usando um paquímetro Mitutoyo com precisão de $\pm 0,01 \mathrm{~mm}$. A resistência mecânica foi determinada por compressão diametral em uma máquina de ensaios universal Instron 5582 usando uma velocidade de carregamento de $0,5 \mathrm{~mm} / \mathrm{min}$.

A microestrutura da superfície de fratura das amostras queimadas foi caracterizada por microscopia eletrônica de varredura (MEV), usando o equipamento Jeol modelo JSM-6460 LV do Programa de Engenharia Metalúrgica e de Materiais da COPPE/UFRJ.

A identificação das fases cristalinas nas peças sinterizadas foi realizada por difração de raios-X (DRX) usando um equipamento Bruker-AXS D5005 equipado com espelho de Goeble para feixe paralelo de raios-X, nas seguintes condições de operação: radiação CoK $\alpha$ (35 kV/40 mA), velocidade do goniômetro de $0,02^{\circ} 2 \theta$ por passo com tempo de contagem de 1,0 segundo por passo e coletados de 5 a $80^{\circ} 2 \theta$.

\section{RESULTADOS E DISCUSSÃO}

A Tabela 3 apresenta a densidade a seco das composições estudadas. Pode ser visto nesta tabela que praticamente não houve mudança no grau de empacotamento da composição com $10 \%$ de incorporação de cinza na massa cerâmica quando comparada à composição A0C (apenas massa cerâmica). Já a composição A20C325 apresentou densidade a seco inferior à massa cerâmica.

Tabela 3: Densidade a seco das composições estudadas $\left(\mathrm{g} / \mathrm{cm}^{3}\right)$.

\begin{tabular}{|c|c|c|c|}
\hline & A0C & A10C325 & A20C325 \\
Densidade a seco $\left(\mathbf{g} / \mathbf{c m}^{3}\right)$ & $1,92 \pm 0,02$ & $1,89 \pm 0,02$ & $1,80 \pm 0,02$ \\
\hline
\end{tabular}

A Figura 1 apresenta a retração diametral dos corpos de prova sinterizados em função do teor de cinza incorporada. É observado que a retração diametral aumentou significativamente com a temperatura. Isto é uma conseqüência do processo de sinterização. A $900^{\circ} \mathrm{C}$, utilizando a barra de erro estatístico, a adição de $10 \%$ de cinza na massa cerâmica não mudou a retração diametral. A $1050^{\circ} \mathrm{C}$, houve um ligeiro aumento da retração com a incorporação de cinza. Isto pode ser devido ao tamanho de partícula da cinza (inferior a 44 $\mu \mathrm{m})$ ter contribuído para o mecanismo de sinterização. Já a $1200^{\circ} \mathrm{C}$, houve um decréscimo da retração com a incorporação de cinza. Nessa temperatura, pode ser observado que as composições com incorporação de 10 e 20\% de cinza apresentam praticamente a mesma retração diametral.

Em geral, observa-se que apenas na temperatura de $1200^{\circ} \mathrm{C}$ é que houve maior diferença na retração diametral dos corpos de prova, sem e com incorporação de cinza. A massa cerâmica A0C apresenta uma retração diametral mais significativa a $1200^{\circ} \mathrm{C}$, devido, principalmente, à grande quantidade de partículas finas, menores que $2 \mu \mathrm{m}$, conhecidas como argilominerais, que são extremamente reativas durante o processo de sinterização.

A Figura 2 apresenta a absorção de água em função da porcentagem de cinza incorporada na massa cerâmica. Observa-se que a absorção diminuiu com a temperatura de sinterização, sendo os resultados mais significativos a $1200^{\circ} \mathrm{C}$. A $900^{\circ} \mathrm{C}$ houve um aumento da absorção de água com a incorporação de cinza. Já a 1050 e a $1200^{\circ} \mathrm{C}$ houve uma ligeira diminuição da absorção para A10C325 e um ligeiro aumento para A20C325. Portanto, 10\% de cinza na massa cerâmica atuou no sentido de fechar a porosidade aberta. Os valores de absorção de água estão relacionados com a efetivação do processo de sinterização por fase líquida.

A Figura 3 mostra os valores de resistência à compressão diametral em função da porcentagem de cinza incorporada à massa cerâmica. Em todas as temperaturas estudadas houve um decréscimo da resistência à compressão com a incorporação de cinza. Pode ser observado que a resistência mecânica aumentou com a temperatura de sinterização, com exceção da composição A20C325, que apresentou valores de compressão diametral a $1050^{\circ} \mathrm{C}$ próximos dos valores a $1200^{\circ} \mathrm{C}$. Isto indica que, embora a absorção de água da composição A20C325 queimada a $1200^{\circ} \mathrm{C}$ foi bem mais expressiva do que a absorção a $1050^{\circ} \mathrm{C}$, o aumento da temperatura de $1050^{\circ} \mathrm{C}$ para $1200^{\circ} \mathrm{C}$ não influenciou nos resultados de compressão diametral para essa composição. Esse resultado pode ser atribuído à presença de partículas de quartzo, principal constituinte mineralógico da cinza, que pode estar atuando como defeito crítico. 


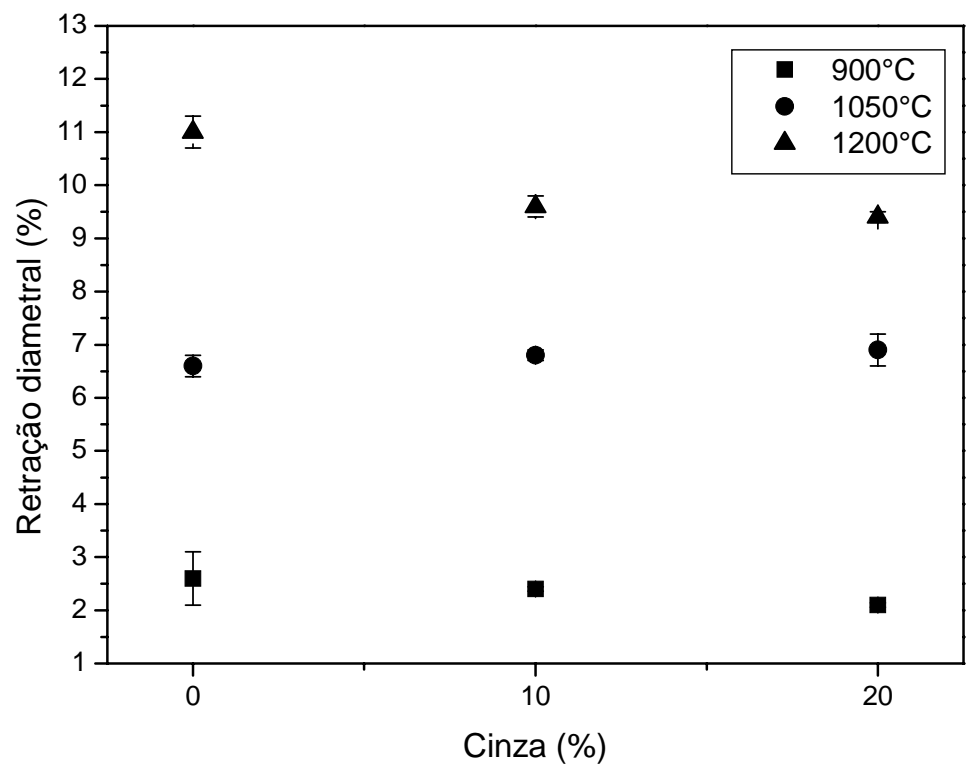

Figura 1: Retração diametral dos corpos de prova sinterizados

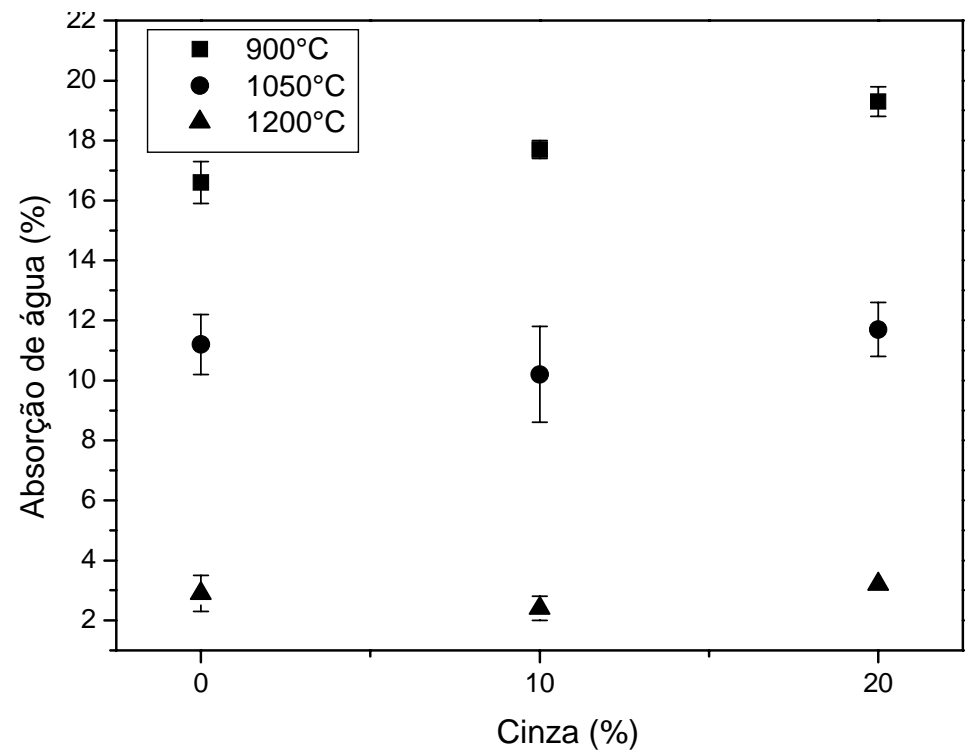

Figura 2: Absorção de água dos corpos de prova sinterizados

A $1200^{\circ} \mathrm{C}$, considerando a barra de erro estatístico, é observado que a composição A10C325 apresentou praticamente a mesma resistência mecânica da composição A0C (massa cerâmica). Provavelmente, nessa temperatura, ocorreu maior formação de fase líquida da A10C325. A composição A10C325, aparentemente, apresentou maior densificação do que a composição A20C325. Isso mostra que 20\% de cinza do bagaço de cana é uma quantidade alta para ser adicionada na massa cerâmica. 


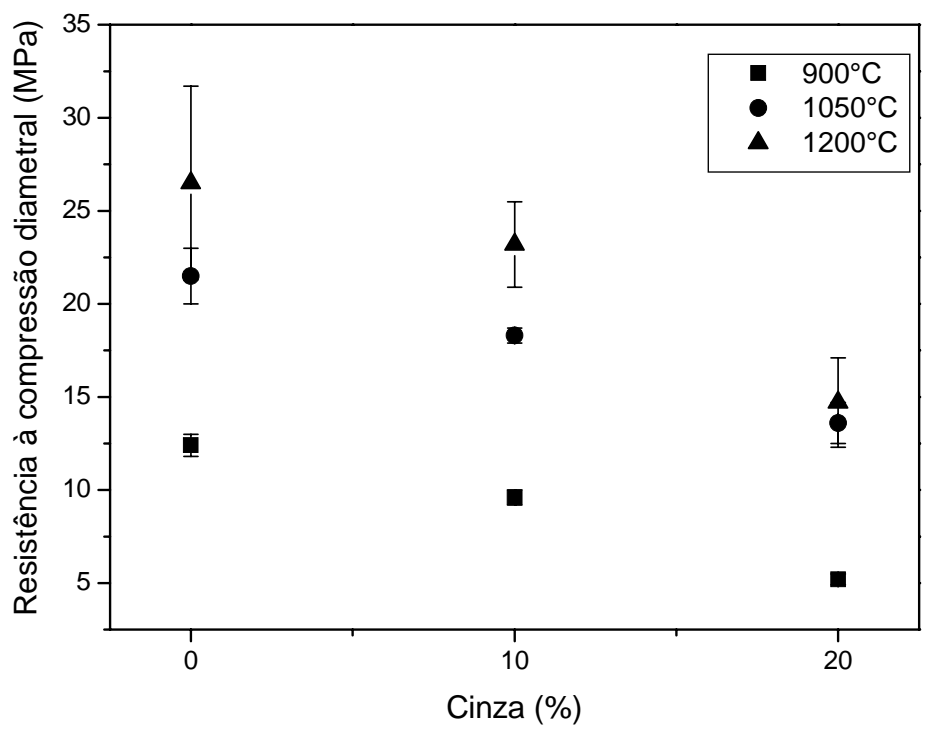

Figura 3: Resistência mecânica por compressão diametral dos corpos de prova sinterizados

As Figuras 4 a 9 apresentam as micrografias da superfície de fratura da cerâmica sem e com adição de cinza de bagaço de cana de açúcar, sinterizadas a 1050 e $1200^{\circ} \mathrm{C}$. Em particular, as Figuras 4 a 6 mostram micrografias das cerâmicas com incorporação de 0 , 10 e $20 \%$ de cinza queimadas a $1050^{\circ} \mathrm{C}$. Pode ser observado que a composição A0C (massa cerâmica sem incorporação) apresenta uma superfície de fratura rugosa. Isso é esperado para materiais argilosos queimados a essa temperatura. Nessa temperatura, a quantidade de fase líquida e sua viscosidade não são suficientes para fechar a porosidade aberta. Nas micrografias da cerâmica com cinza (Figura 5 e 6) nota-se uma heterogeneidade, aglomerados, indicando que a temperatura de $1050^{\circ} \mathrm{C}$ não foi suficiente para produzir sinterização líquida total, e sim, parcial.

As Figuras 7 a 9 apresentam as micrografias das cerâmicas com incorporação de 0,10 e $20 \%$ de cinza queimadas a $1200^{\circ} \mathrm{C}$. Nas micrografias da composição A0C nota-se sinterização líquida, porém, insuficiente para preenchimento dos poros, necessitando de adição de fundentes. Já a composição A10C325 (com cinza) apresenta maior formação de fase líquida. A sinterização via fase líquida ainda foi insipiente e insuficiente para evitar a seqüência contínua de poros angulares que, provavelmente, foi responsável pela fratura. A composição A20C325 apresenta uma quantidade de líquido significativa, a amostra está vitrificada, porém, com a presença de grande volume de poros decorrentes da contração das cinzas na sua liquefação. Este grande volume de poros, vários deles contínuos, pode ser a falha responsável pela redução da resistência mecânica.
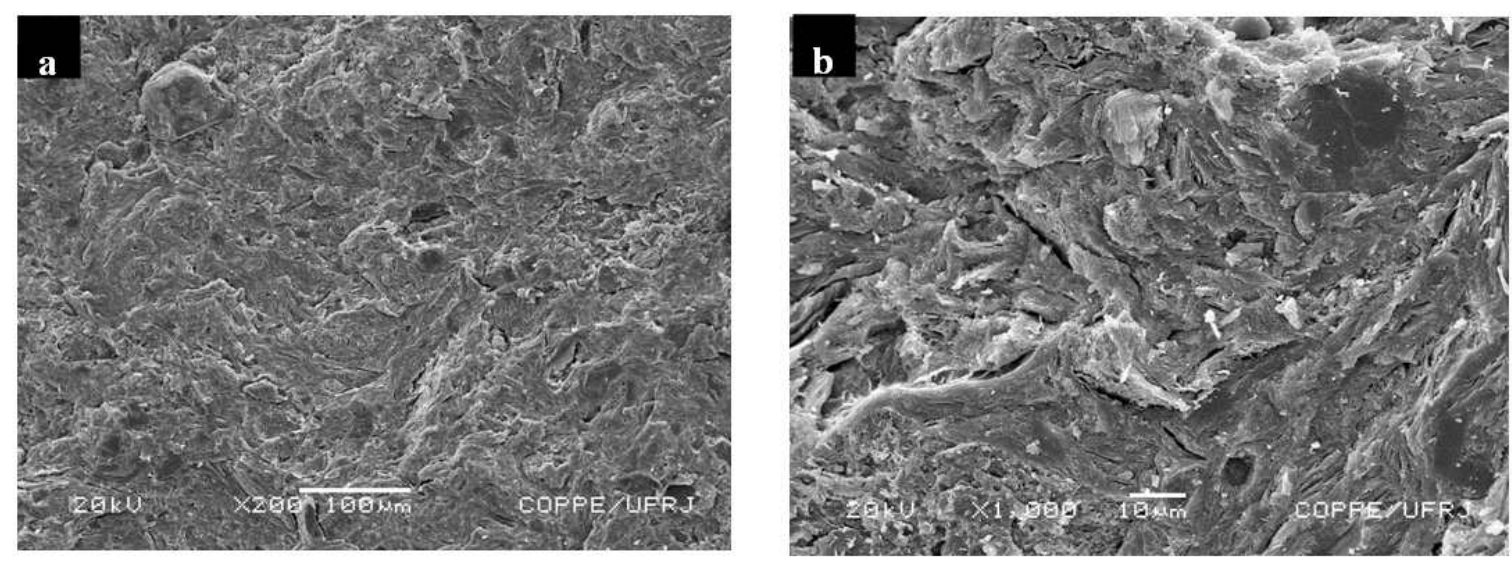

Figura 4: Micrografias da região de fratura da composição A0C sinterizada a $1050^{\circ} \mathrm{C}$. (a) 200x; (b) 1.000x. 

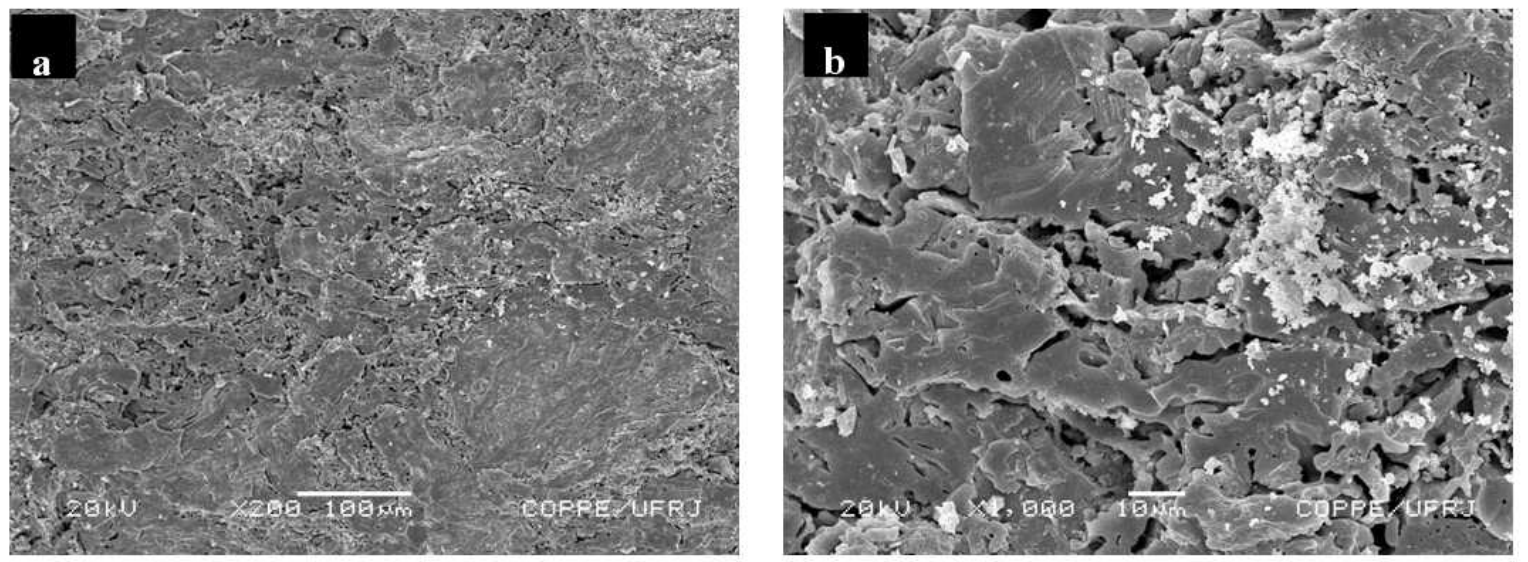

Figura 5: Micrografias (MEV) da região de fratura da composição A10C325 sinterizada a $1050^{\circ} \mathrm{C}$. (a) $200 x$; (b) $1.000 x$.
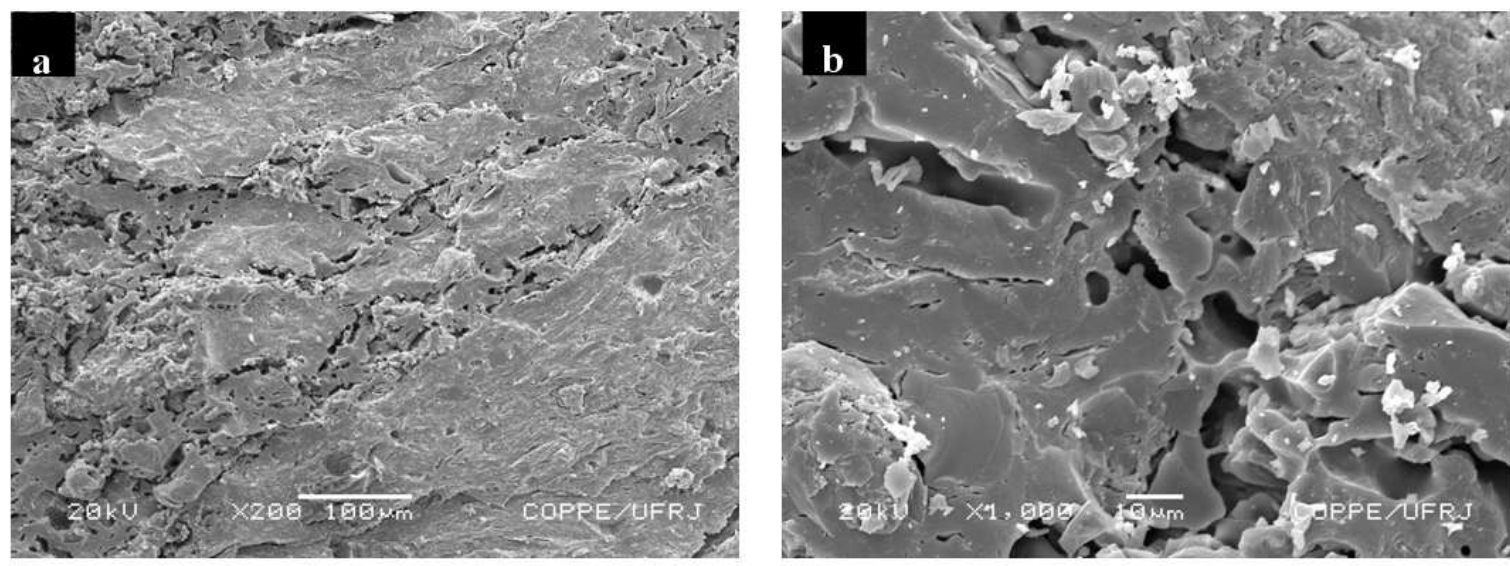

Figura 6: Micrografias (MEV) da região de fratura da composição A20C325 sinterizada a $1050^{\circ} \mathrm{C}$. (a) $200 x$; (b) $1.000 x$.
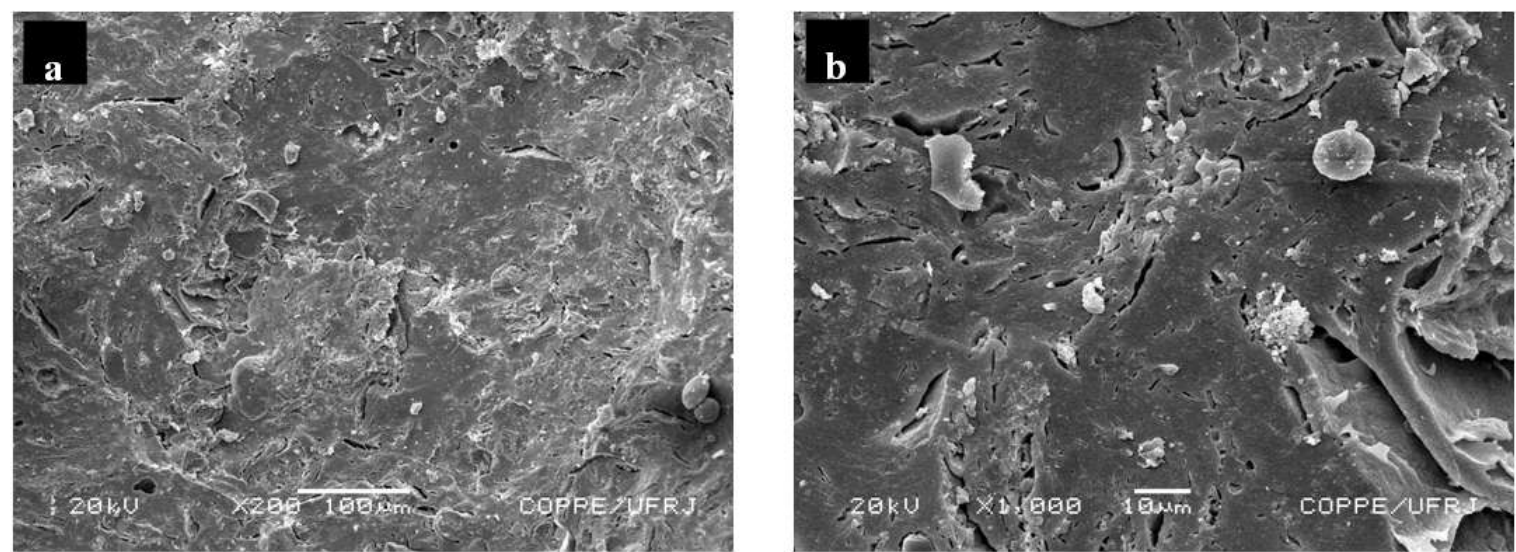

Figura 7: Micrografias (MEV) da região de fratura da composição A0C sinterizada a $1200^{\circ} \mathrm{C}$. (a) $200 \mathrm{x}$; (b) $1.000 \mathrm{x}$. 

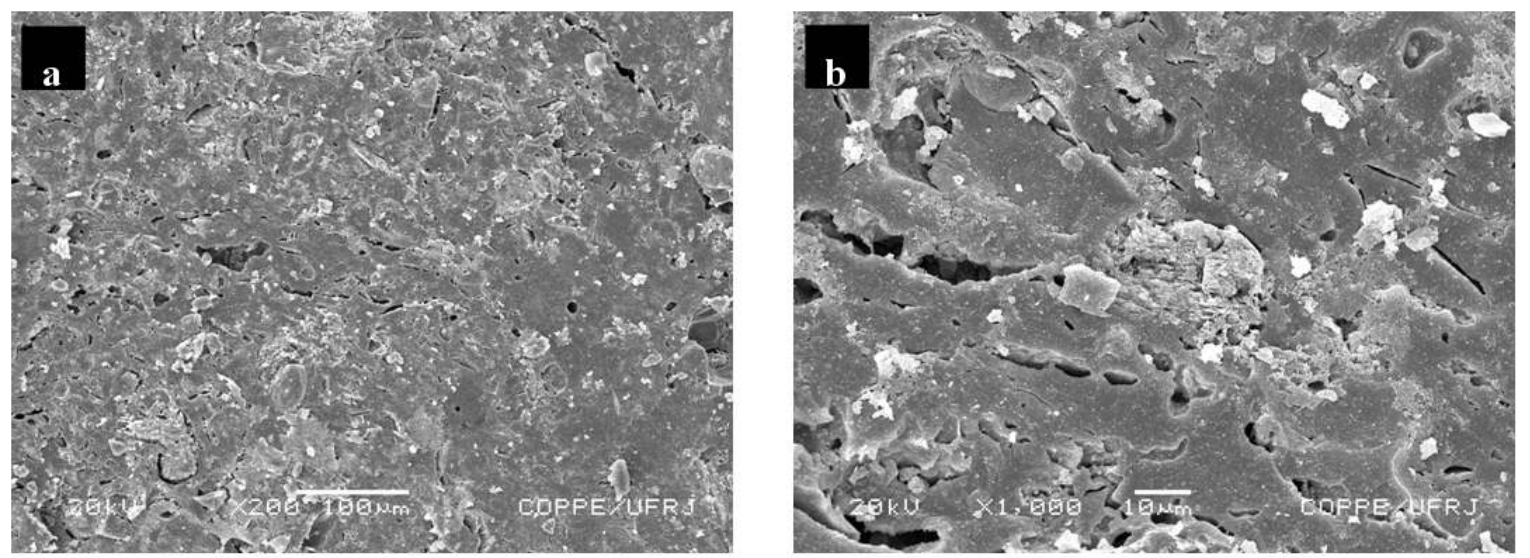

Figura 8: Micrografias (MEV) da região de fratura da composição A10C325 sinterizada a $1200^{\circ} \mathrm{C}$. (a) $200 x$; (b) $1.000 x$.
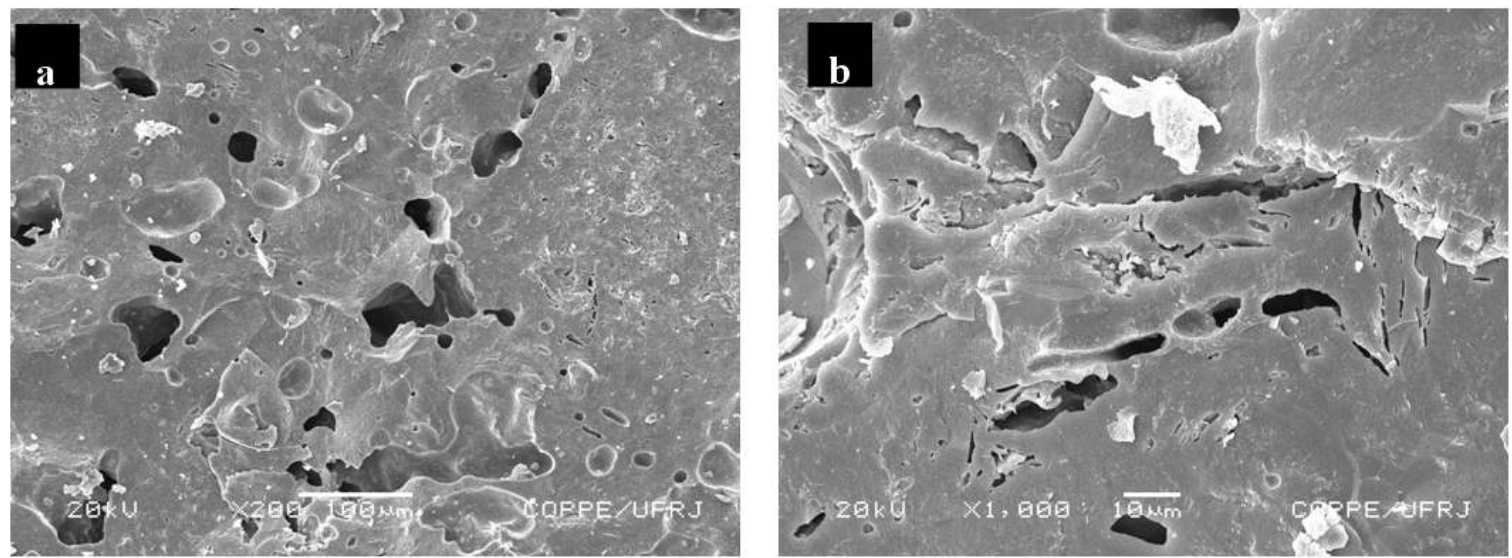

Figura 9: Micrografias (MEV) da região de fratura da composição A20C325 sinterizada a $1200^{\circ} \mathrm{C}$. (a) 200x; (b) $1.000 x$.

As Figuras 10 e 11 apresentam os difratogramas de raios-X (DRX) das composições A0C, A10C325 e A20C325 sinterizadas a 1050 e a $1200^{\circ} \mathrm{C}$, respectivamente. Na Figura 10, as seguintes fases foram identificadas para a composição A0C: mulita, cristobalita, quartzo e hematita. Já para as composições com cinza, sinterizadas a $1050^{\circ} \mathrm{C}$, além das fases identificadas para A0C, também foi identificado aluminossilicato de cálcio. A $1200^{\circ} \mathrm{C}$, para todas as composições estudadas, as fases identificadas foram: mulita, cristobalita, quartzo e hematita. Nota-se que na temperatura de sinterização mais alta, $1200^{\circ} \mathrm{C}$, as composições apresentam maior intensidade dos picos de difração correspondentes a mulita e a cristobalita e menor intensidade dos picos correspondentes ao quartzo. Nessa temperatura, a fase de aluminossilicato de cálcio não foi identificada no DRX. As fases identificadas no DRX estão de acordo com a composição química das matérias-primas, onde ambas apresentam $\mathrm{SiO}_{2}$ em maior porcentagem em sua constituição. A adição de cinza na massa cerâmica não mudou as fases cristalinas majoritárias, apenas houve formação de mais uma fase, na temperatura de $1050^{\circ} \mathrm{C}$, a do aluminossilicato de cálcio. 


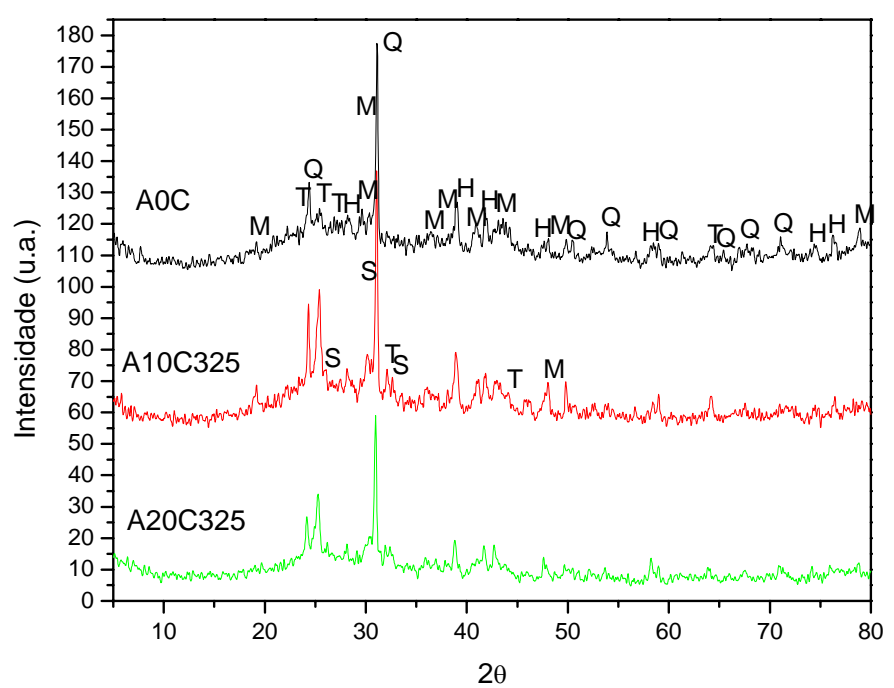

Figura 10: Difratograma de raios-X das composições A0C, A10C325 e A20C325 sinterizadas a $1050^{\circ} \mathrm{C}$. $\mathrm{M}=$ mulita, $\mathrm{C}=$ cristobalita, $\mathrm{Q}=$ quartzo, $\mathrm{H}=$ hematita, $\mathrm{S}=$ aluminossilicato de cálcio.

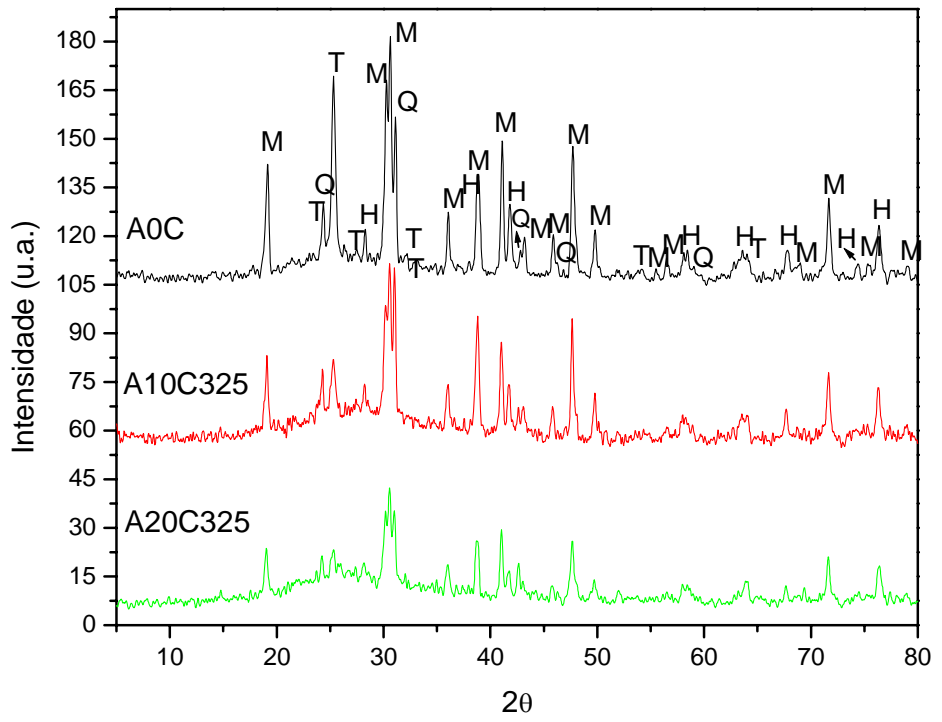

Figura 11: Difratograma de raios-X das composições A0C, A10C325 e A20C325 sinterizadas a $1200^{\circ} \mathrm{C}$. $\mathrm{M}=$ mulita, $\mathrm{C}=$ cristobalita, $\mathrm{Q}=$ quartzo, $\mathrm{H}$ = hematita.

\section{CONCLUSÕES}

Nesse trabalho foi estudada a influência da temperatura de sinterização nas propriedades físicas, mecânicas e microestruturais de cerâmica vermelha incorporada com cinza de bagaço de cana de açúcar. Os resultados permitem as seguintes conclusões:

- Apenas na temperatura de $1200^{\circ} \mathrm{C}$ houve maior diferença na retração diametral dos corpos de prova sem e com incorporação de cinza.

- A 1050 e a $1200^{\circ} \mathrm{C}$ houve uma ligeira diminuição da absorção de água para a composição A10C325 e um ligeiro aumento para a composição A20C325. Portanto, 10\% de cinza na massa cerâmica atuou no sentido de fechar a porosidade aberta.

- Incorporações de até $10 \%$ de cinza na massa cerâmica, sinterizada a $1200^{\circ} \mathrm{C}$, não mudaram a resistência mecânica quando comparada à massa cerâmica, levando em consideração a barra de erro estatístico. 
- A temperatura de sinterização influenciou em todas as composições estudadas, com exceção da composição A20C325, que apresentou valores de compressão diametral a $1050^{\circ} \mathrm{C}$ próximos dos valores a $1200^{\circ} \mathrm{C}$.

- Há necessidade de adição de fundentes na massa cerâmica para maior formação de quantidade de fase líquida.

- Para as composições com cinza, a temperatura de $1050^{\circ} \mathrm{C}$ é baixa para uma formação de fase líquida mais eficiente, sendo que nessa temperatura há alta heterogeneidade do material com significativo volume de poros angulares e quase contínuos. A porosidade angular é devido à viscosidade alta.

- A $1200^{\circ} \mathrm{C}$, a composição A10C325 (com 10\% de cinza) apresenta uma maior formação de fase líquida, sendo ainda insipiente e insuficiente para evitar a seqüência contínua de poros angulares. Já a composição A20C325 (com 20\% de cinza) apresenta uma quantidade de líquido significativa, porém, com a presença de grande volume de poros decorrentes da contração das cinzas na sua liquefação que, provavelmente, foi o responsável pela fratura, para todas as composições com cinza estudadas.

Em geral, não houve mudanças significativas nas propriedades físicas e mecânicas estudadas de cerâmica vermelha com a incorporação de cinza do bagaço de cana de açúcar com granulometria inferior a $44 \mu \mathrm{m}$ (325 mesh).

\section{AGRADECIMENTOS}

Os autores agradecem ao CNPq, CAPES, FAPERJ e FENORTE/TECNORTE o apoio financeiro e bolsas concedidas a esta pesquisa.

\section{BIBLIOGRAFIA}

[1] FEEMA - FUNDAÇÃO ESTADUAL DE ENGENHARIA DO MEIO AMBIENTE, Programas $e$ Projetos, Qualidade do ar, 2006, http://www.feema.rj.gov.br/qualidade_do_ar.htm Acessado em fevereiro de 2006.

[2] SOARES, J.M.D., QUINTANA, L.M.H., RAMPAZZO, M. "Avaliação de Blocos Cerâmicos com Adição de Cinza de Casca de Arroz”, In: Anais do $44^{\circ}$ Congresso Brasileiro de Cerâmica, pp. 15501, São Pedro, SP, Maio de 2000.

[3] DONDI, M., ERCOLANI, G., GUARINI, G., et al. "Orimulsion Fly ash in Clay Bricks—Part 1: Composition and Thermal Behaviour of Ash", Journal of the European Ceramic Society, v. 22, pp. 1729-1735, 2002.

[4] DONDI, M., GUARINI, G., RAIMONDO, M., et al. "Orimulsion Fly ash in Clay Bricks—Part 2: Technological Behaviour of clay/ash Mixtures", Journal of the European Ceramic Society, v. 22, pp. 1737-1747, 2002b.

[5] DONDI, M., GUARINI, G., RAIMONDO, M., et al. "Orimulsion Fly ash in Clay Bricks-Part 3: Chemical Stability of ash-bearing Products”, Journal of the European Ceramic Society, v. 22, pp. 1749-1758, 2002.

[6] PINATTI, D.G., CONTE, R.A., BORLINI, M.C., et al. "Incorporation of the ash from Cellulignin into Vitrified Ceramic Tiles”, Journal of the European Ceramic Society, v. 6, n. 3, pp. 305-310, 2006.

[7] BORLINI, M.C., SALES, H.F., VIEIRA, C.M.F., et al. "Use of Biomass Ashes as an Addition to Red Ceramics", In: Global Symposium on Recycling, Waste Treatment and Clean Technology REWA'S 2004, pp. 767-774, Madrid, Espanha, 2004.

[8] SCHNEIDER JÚNIOR, S.J., Engineered Materials Handbook, Ceramics and Glass, Ed. ASM International, USA, 2000.

[9] ASTM - American Society for Testing and Materials, Water Absorption, Bulk Density, Apparent Porosity, and Apparent Specific Gravity of Fired Whiteware Products, C 373-72, 1972, USA. 